Thorax (1952), 7, 43.

\title{
THE BRONCHODILATOR ACTION OF KHELLIN
}

\author{
BY \\ M. C. S. KENNEDY AND J. P. P. STOCK \\ From the M.R.C. Silicosis Treatment Centre, Stoke-on-Trent, and the City General \\ Hospital, Stoke-on-Trent
}

(RECEIVED FOR PUBLICATION SEPTEMBER 5, 1951)

This paper describes a preliminary investigation into the bronchodilator action of khellin in patients with clinical bronchospasm.

Khellin is one of the active principles of the plant Ammi visnaga (Linn.), which grows wild in many eastern Mediterranean countries. Simple decoctions of its seeds have apparently been used by the local native populations for generations as a spasmolytic, in particular for the relief of ureteric colic. The recent interest awakened in its possible therapeutic applications has been largely due to the work of Anrep, Barsoum, Kenawy, and Misrahy (1946, 1947); Anrep, Barsoum, and Kenawy (1949).

A number of crystalline substances have been isolated from the seeds (Späth and Gruber, 1938, 1941a and b). Pharmacologically, the most active of these is khellin, which was first isolated by Mustapha in 1879, and chemically is di-methoxy-methylfurano-chromone. Two principal therapeutic properties have been claimed for this substance. It is said to dilate the coronary arteries and to relax smooth muscle throughout the body, including that of the bronchi. Anrep and others, working on guinea-pig lungs, showed that khellin was a bronchodilator with an activity four to six times greater than that of theophylline-with-ethylenediamine. Weight for weight, however, it was considerably weaker than adrenaline, $4 \mu \mathrm{g}$. of khellin being approximately equivalent to $0.01 \mu \mathrm{g}$. of adrenaline. They found the drug to be rapidly absorbed by the intramuscular or oral route and stated that its rate of excretion or destruction in the body is slow, so that with continued administration it tends to be cumulative. Kenawy, Barsoum, and Bagoury (1950) have reported favourably on the treatment of bronchial asthma with khellin, and Rosenman, Fishman, Kaplan, Levin, and Katz (1950) have described good results in the treatment of chronic cor pulmonale.

We were encouraged to begin this investigation by the dramatic improvement observed in a case with severe clinical bronchospasm, following the oral administration of khellin.* The patient, a man aged 58 years, had been in hospital under the care of one of us for three months with severe continuous asthma, unresponsive to any of the usual remedies. He remained persistently orthopnoeic, wheezing, cyanosed, and distressed, and required oxygen almost continuously. Twenty-four hours after beginning oral khellin, $50 \mathrm{mg}$. thrice daily, his dyspnoea, orthopnoea, and wheezing disappeared and he lay flat for the first time for many months.

* Throughout this work we have used "benecardin" (Benger Laboratories, Ltd.), a presentation of khellin in tablet and ampoule form containing $95 \%$ khellin assayed by a modified colorimetric method. 


\section{DEFINITION}

It is usually accepted that narrowing of the lumina of the bronchioles gives rise to a clinical picture which is characterized by a sense of tightness in the chest, associated with an audible wheeze, inspiratory and expiratory rhonchi, and varying degrees of dyspnoea. Several factors may contribute to the pathogenesis of this functional narrowing of the smaller bronchi, and include the presence of tenacious exudate lining the mucosa, allergic or inflammatory oedema of the mucous membrane itself, or contraction of the smooth muscle of the bronchial walls (i.e. bronchospasm). Since it is rarely possible on clinical grounds to determine the relative importance of these various factors in a given case, for the purpose of this communication we shall employ the term "bronchoconstriction" to denote any reversible generalized narrowing of the smaller bronchi causing this clinical picture.

\section{METHOD}

In attempting to assess the effect of any alleged bronchodilator, it is clearly desirable to have some measurable objective index of the presence and degree of bronchoconstriction. Clinical criteria are unreliable and cannot give more than an approximate indication of the degree of bronchoconstriction. The oldest objective test to be used in the clinical study of bronchodilator drugs is the simple vital capacity measurement. Taken alone, however, this is an imperfect and occasionally misleading index of the patient's ventilatory capacity (Gilson and Hugh-Jones, 1949). More recently, measurement of the total lung volume and its various subdivisions has been used (Whitfield, Arnott, and Waterhouse, 1950), but this is a difficult and tedious procedure which cannot readily be adapted for routine clinical work.

It has been pointed out by Sheldon and Otis (1951) that a theoretically ideal test for assessing changes in the bronchial diameter is one that measures the resistance of the respiratory tract to air flow. However, one of the main physiological effects of narrowing of the smaller bronchi is to reduce the maximum rate at which the

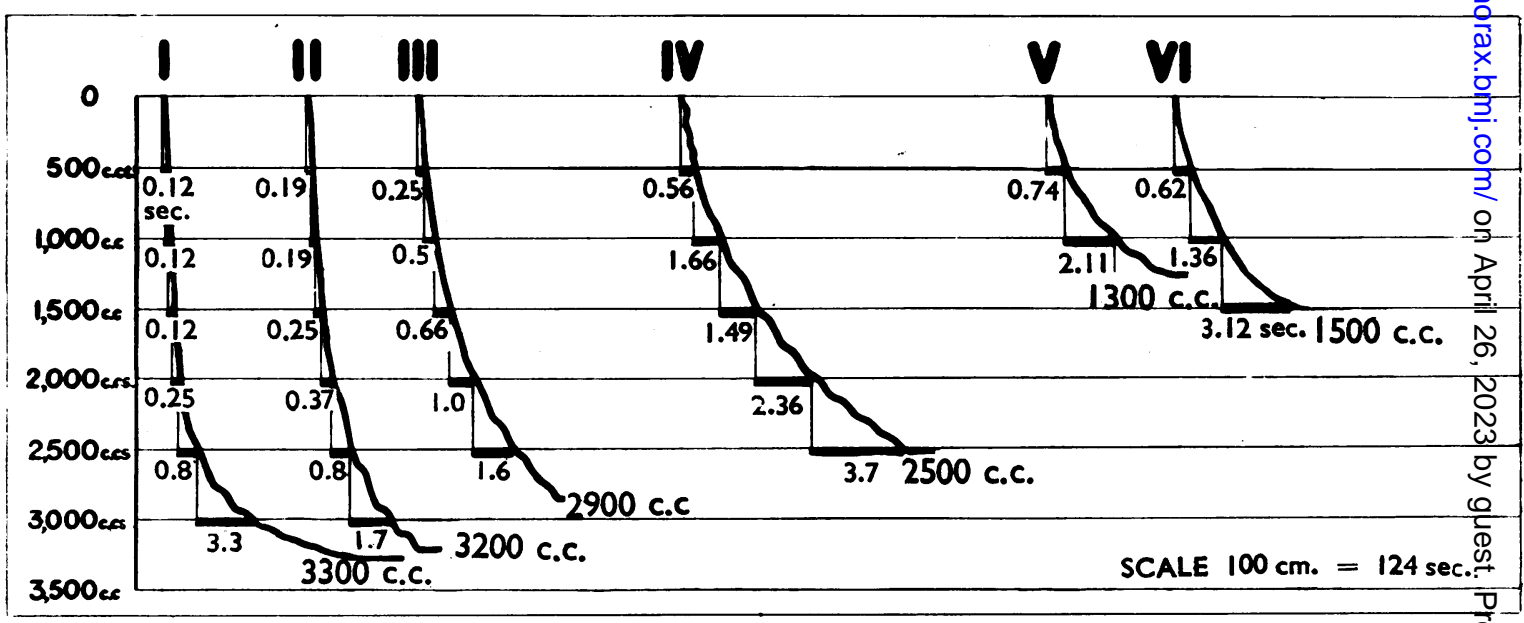

FIG. 1.-Forced fast tracings of vital capacities exemplifying varying degrees of disability. any patients described in this paper.

They are not relate $\$$ 
lungs can be filled and emptied of air. Variations in the bronchial lumen will thus be reflected in corresponding variations in the maximum ventilatory capacity which the patient can achieve. Therefore, in assessing a supposed bronchodilator, it seems reasonable to take the maximum ventilatory capacity as an index of the degree of bronchoconstriction existing before, during, and after treatment with the drug under trial.

The maximum breathing capacity test (M.B.C.) as introduced by Hermannsen in 1933, and more recently described by other workers (Comroe, 1950), is the accepted method in current use for assessing the maximum ventilatory capacity. In this test the volume of air shifted over a short time interval is measured while the patient is breathing as deeply and as quickly as possible. The result is expressed in litres per minute. However, the M.B.C. test has the disadvantage of being fatiguing and time-consuming to both patient and observer, and further, there appears to be a considerable "learning" effect, which is a disadvantage in outpatient work.

Kennedy (1949) suggested that it might be possible to predict the patient's maximum breathing capacity from the analysis of single expiratory vital capacity tracings recorded on a fast-moving kymograph, and Fig. 1 shows examples of tracings in six subjects. From the examination of many hundreds of such tracings it was found that they could, in general, be divided into three fractions as shown in Fig. 2. In the first fraction of the tracing the flow rate is maximum and relatively uniform. The second fraction is generally curved, and is less steep than the first, but the third or terminal fraction is undulatory. It was shown that the slope of the first steep fraction of the curve appeared to determine the patient's maximum breathing capacity.

During the past two years various methods of recording and analysing these tracings have been studied to obtain a valid measure of ventilatory capacity (Kennedy, 1951). However, all that need be said here is that half the mean expiratory flow rate (E.F.R.) expressed in litres/minute, measured over the first 0.75

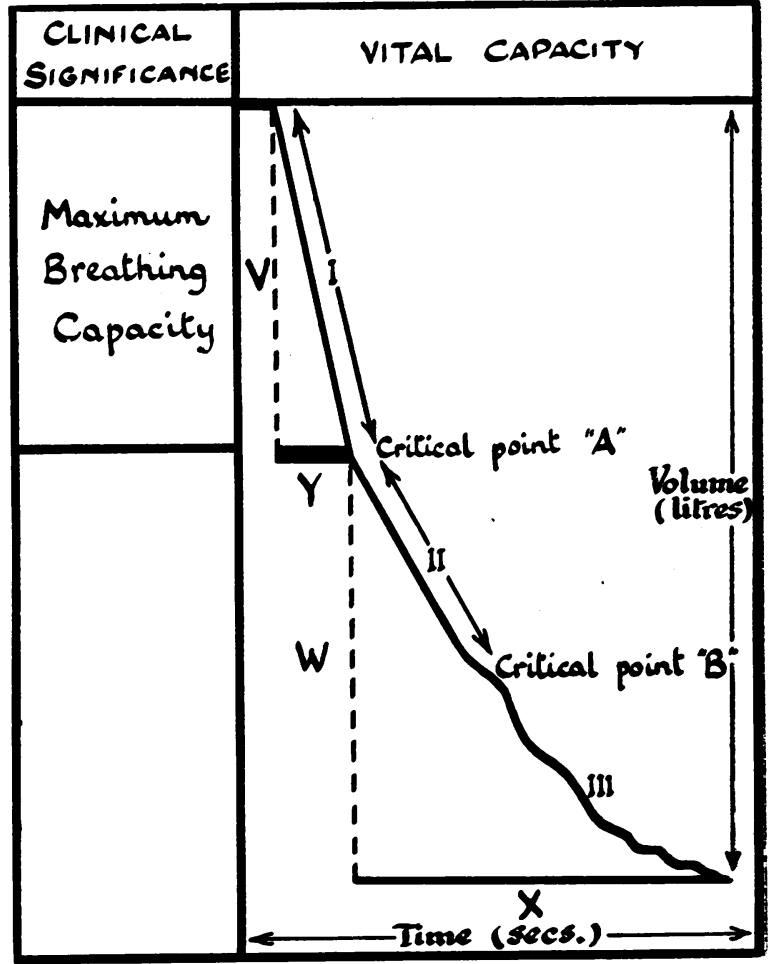

FIG. 2.-Diagrammatic sketch of a vital capacity tracing. The section marked $I$ is that used in estimating the expiratory flow rate. 


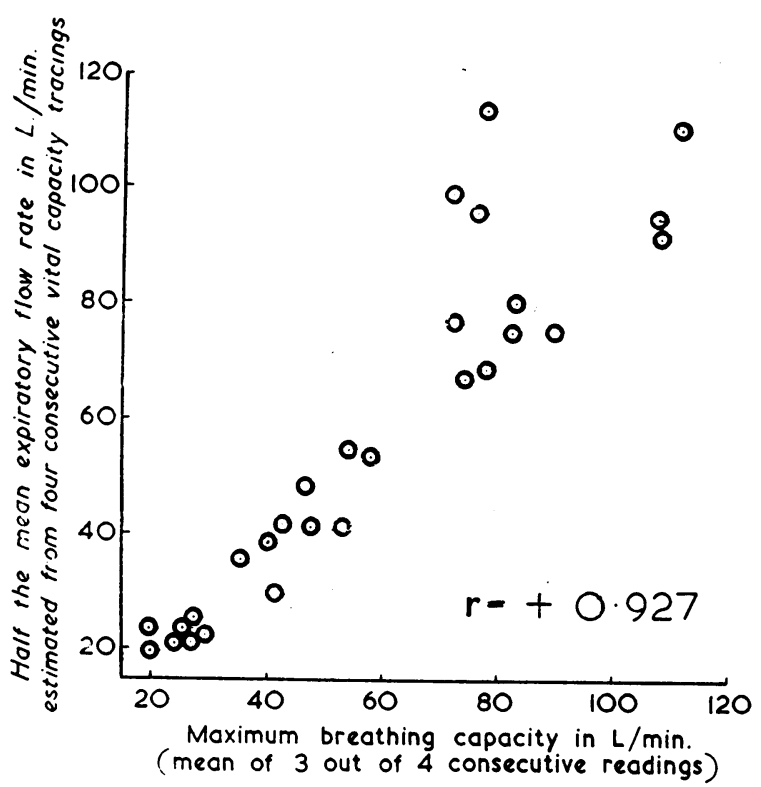

FIG. 3.-Relationship between E.F.R. and M.B.C. in 30 male subjects. M.B.C. was estimated by the method described by Gilson and Hugh-Jones (1949) with a standard error of $\pm 5 \%$. We have, therefore, adopted this method as our principal objective measure for assessing the bronchodilator effect of khellin.

We have also recorded the vital capacity and, in many instances, the observed maximum breathing capacity, and some of these data will be presented.

It is, of course, known that the expiratory flow rate is determined by a number of factors in addition to the lumen of the bronchial tree, as, for example, by the tone of the expiratory musculature, the rigidity of the chest wall, and the power of elastic recoil of the lung. We, therefore, felt that we should attempt to assess, when investigating a patient, the degree of reversible bronchoconstriction present as opposed to other irreversible changes affecting the air-flow rate. Theoretically, it should be possible to assess the degree of reversible bronchoconstriction in a given patient by measuring the ventilatory capacity before and again after the administration of a proved bronchodilator. This has been attempted by employing a modification of Rossier and Méan's adrenaline test (1936). In this modification the expiratory air-flow rate is measured before and after a 15-minute inhalation of a $1 / 1,000$ solution of adrenaline.* Fig. 4 is an example of changes in the expiratory air-flow rate following the inhalation of adrenaline.

* Throughout this investigation " apneugene" has been used. This is a proprietary preparation consisting of adrenaline, $1 / 1,000$, with anaesthesin $1 \%$. 


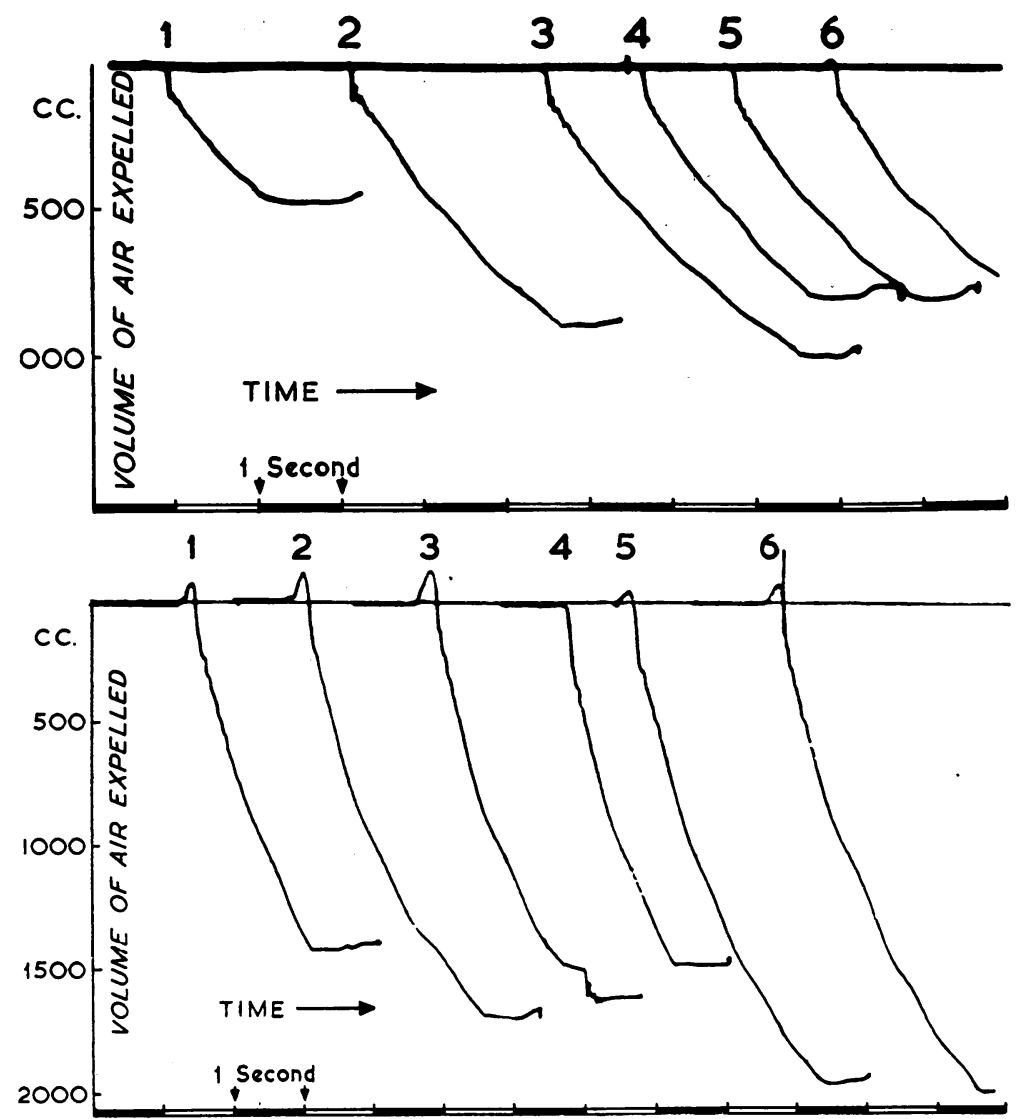

FIG. 4.-Example of method for evaluating the effect of adrenaline. Half the E.F.R. is measured ov:r the îrst three-quarter second period of expiration from each of the six tracings obtained before the inhalation of adrenaline, and again from the six tracings after the inhalation of adrenaline. The E.F.R. values obtained from these tracings are tabled below, and also the final mean value corrected for temperature.

Table

\begin{tabular}{|c|c|c|c|}
\hline Expiratory Tracings & $1 \quad 2 \quad 3 \quad 4535$ & Mean Value & $\begin{array}{l}\text { Mean Value } \\
\text { Corrected }\end{array}$ \\
\hline $\begin{array}{l}\text { Before adrenaline }\} \text { Half E.F.R. in litres/min. }\{ \\
\text { After adrenaline }\}\end{array}$ & $\begin{array}{llllll}12 & 14 & 14 & 16 & 16 & 16 \\
30 & 34 & 34 & 38 & 36 & 36\end{array}$ & $\begin{array}{l}14.6 \\
34 \cdot 6\end{array}$ & $\begin{array}{l}16 \\
39\end{array}$ \\
\hline
\end{tabular}

\section{PROCEDURE}

In general, the procedure adopted in the study of each patient falls under three main headings : (1) a pre-trial assessment to obtain "base-line" data ; (2) the effect of a single intramuscular injection of khellin on the first day of trial ; (3) the subsequent progress on alternating courses of oral khellin and placebo tablets. 
(1) The Pre-trial Assessment.-The expiratory flow rate, vital capacity, and maximum breathing capacity of patients who had been clinically selected for trial were measured before and after an adrenaline inhalation on two or more different days before treatment with khellin. The purpose of the adrenaline test here was both to determine whether the patient had reversible bronchoconstriction and also to provide a possible yardstick against which we could measure the effect of khellin. Further, from the study of the E.F.R. values on different days before giving adrenaline, we hoped to obtain a measure of the day-to-day variability of the degree of bronchoconstriction and a "base-line" value.

(2) Effect of a Single Intramuscular Injection of Khellin.-Each patient was clinically and objectively assessed before and half an hour after an injection of sterile water. The patient was then given an intramuscular injection of khellin and the assessment was repeated a quarter of an hour later and thereafter at intervals of half to three-quarters of an hour over a three- to four-hour period. At the end of the period of observation a final assessment was carried out after a 15-minute inhalation of adrenaline. In the clinical assessment at each of these times, changes of colour, dyspnoea, wheezing, and audible rhonchi were noted. For the objective assessment, the E.F.R., vital capacity (V.C.), and blood pressure were measured on each occasion. The assessments before and after the injection of water were made to provide further data for the "base-line" and to exclude the possibility of any response to the injection of khellin being psychological in origin.

(3) Subsequent Progress on Oral Khellin and Placebo.-Twenty-four to 48 hours after the intramuscular injection of khellin, the patient was again assessed clinically and objectively. He was then given oral khellin for approximately a week and then changed, without his knowledge, to placebo tablets for a further week. Another course of oral khellin was then given, usually with an increased dose. Throughout this period the patients were asked to attend three times each week for objective assessment, when the E.F.R. and V.C. were measured before and after an adrenaline inhalation. The observer making these measurements did not know whether the patients were receiving khellin or placebo tablets.

This is the broad outline of the trial as originally planned. Unfortunately, however, for various reasons some patients were unable to adhere strictly to this routine. More recently blood levels of the drug have been estimated following both intramuscular and oral medication.

\section{CLINICAL MATERIAL}

In most cases of asthma bronchoconstriction tends to be an ephemeral and elusive manifestation with wide and unpredictable fluctuations, both throughout the 24 hours and from day to day. Objective measurements in such cases, therefore, made at arbitrary times and on arbitrary dates are likely to show considerable spontaneous variations, independent of therapy. Since these woukd make it difficult to distinguish the effects of treatment and control periods from the natural history of the disease, at least without prolonged observation, we decided to select for investigation cases showing a persistent and relatively stable bronchoconstriction with, as far as possible, infrequent severe attacks. Thus the main criterion deter- 
mining the selection of cases was that they should constantly present those clinical features generally regarded as evidence of bronchospasm or mucosal oedema, including persistent "wheezy" breathing, inspiratory and expiratory rhonchi, and a variable degree of dyspnoea. All cases also showed a positive response to the adrenaline test which was taken as confirmatory evidence of the presence of reversible bronchoconstriction.

Twelve patients were chosen for the initial trial and comprise a somewhat heterogeneous series taken partly from a medical out-patient clinic and partly from patients attending a silicosis unit. Broadly speaking, they fall into two groups : the first, chronic asthmatics showing evidence of persistent bronchoconstriction between their more florid attacks; the second, mainly middle-aged patients with chronic bronchitis and clinical emphysema, with or without pneumoconiosis, in whom a reversible bronchoconstriction was regarded as a significant contributory factor in their disability.

\section{ADMINISTRATION OF KHELLIN}

Throughout this investigation khellin has been administered either by the intramuscular or oral routes. It is relatively insoluble in water, but is soluble in a $50 \%$ solution of sodium salicylate. A 5\% solution of khellin in this vehicle has been used for the intramuscular injections. More recently propylene glycol has been used as the solvent. Oral khellin has been given as 25 or $50 \mathrm{mg}$. tablets with lactose. The placebo tablets consisted of lactose only. The intramuscular dose has varied between 150 and $400 \mathrm{mg}$. The oral dose has largely been determined by the patient's tolerance and has varied from 50 to $400 \mathrm{mg}$. daily.

\section{RESULTS}

The changes in the E.F.R. and V.C. findings have been charted graphically for all 12 patients. From the graphs, five out of the 12 appeared to be improved after the intramuscular or oral administration of khellin, and have been re-numbered 1 to 5 , and the changes in E.F.R. in relation to their treatment shown in Figs. 5 to 9, and summarized in Table I.

\section{PATIENTS IMPROVED BY KHELlin}

Patient No. 1.-A man, aged 45, who suffered from chronic bronchitis and emphysema, had been dyspnoeic on the slightest exertion for the past two to three years. The baseline level for this patient has been estimated from the mean of six E.F.R. values. These six E.F.R. values consist of the four E.F.R. values (before the inhalation of adrenaline) which were recorded on different days before the first day of trial, together with two E.F.R. values recorded on the first day of the trial, which were recorded before and after an injection of sterile water. As can be seen from Table I, the mean of these six values gives a base-line level of 17.1 per min., with a range of 16.1 per min. to 18.1 per min.* The values for his E.F.R. during the time he was observed can be seen plotted on his graph. There was no clinical or objective evidence of improvement for three hours

* The normal value of the E.F.R. varies with age, sex, and build. In a normal healthy male adult, below the age of 40 , it usually lies between 120 to $1801 . / \mathrm{min}$. The resting respiratory level is in the region of $6-81 . / \mathrm{min}$. Consequently, the patient who has a mean E.F.R. of 16-18 $1 . / \mathrm{min}$. has very little ventilatory reserve available for work and exercise. 
following an intramuscular injection of $200 \mathrm{mg}$. khellin. However, later he volunteered the information that in the evening following his injection (i.e. about seven hours later) he was able to walk quickly upstairs, a feat of which he had been incapable for the past two years. He further stated that his breathing was easier on the following two days. Unfortunately, no objective assessment was made 24 hours after the injection, but 40 hours after the injection his E.F.R. before adrenaline was 21 litres per minute and after adrenaline 25 litres per minute, which are the highest values recorded over the whole period of observation (i.e. $23 \%$ improvement over his base-line value, which was 17 litres per minute). He was then -given khellin by mouth for a week, but he was able to tolerate only $150 \mathrm{mg}$. daily for two days, owing to severe nausea and vomiting; the dose was reduced to $50 \mathrm{mg}$. daily, which he tolerated. He was then given the placebo tablets for 10 days, after which he had four further days' treatment with oral khellin. Again he was unable to tolerate $150 \mathrm{mg}$. daily because of nausea and vomiting. He was lost to the trial over-the Christmas recess and succumbed to the influenza epidemic at home on January 1, 1951.

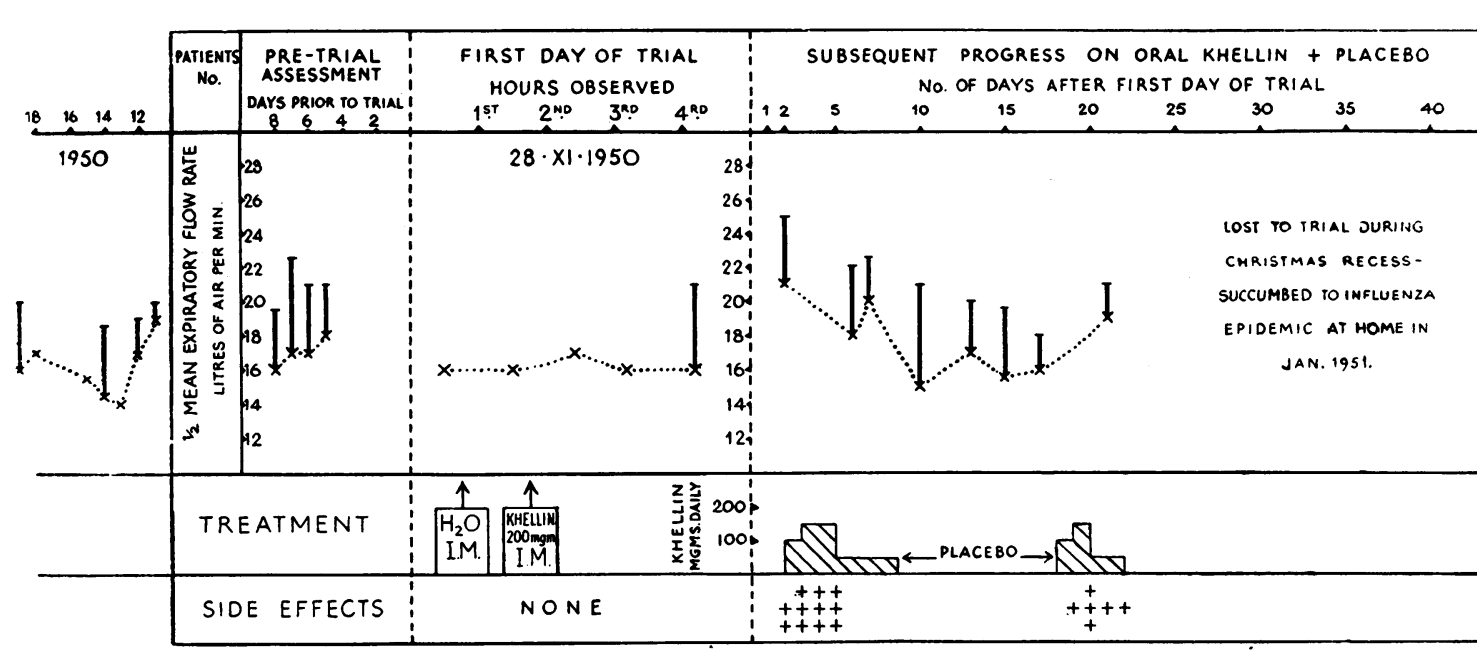

FIG. 5

Patient No. 2.-A man, aged 48, a chronic asthmatic, had been in hospital for three weeks suffering from severe status asthmaticus. Unfortunately it was impracticable to have a pre-trial objective assessment of this patient. On the day of the trial he was cyanotic and dyspnoeic at rest and exhibited marked inspiratory and expiratory rhonchi. His E.F.R. before and after an intramuscular injection of water was 20 and 22 litres per minute respectively. One hour after $200 \mathrm{mg}$. intramuscular khellin his E.F.R. had increased to 30 litres per minute, and two to three hours after injection to 35 litres per minute ; by this time he was no longer cyanosed or dyspnoeic at rest, although rhonchi were still present, but slightly diminished.

Next day his breathing was much improved and he said he felt better than he had for three months. He was then given oral khellin, $50 \mathrm{mg}$. thrice daily for one week, during which time he maintained his clinical improvement. His E.F.R. on the fifth day of oral khellin was found to be 75 litres per minute (i.e. $241 \%$ improvement over his base-line level), which was increased after the inhalation of adrenaline to 99 litres per minute. 
Dúring the period of placebo tablets, his clinical condition deteriorated and his E.F.R. values diminished. When khellin was given again, both clinical condition and E.F.R. values again improved (Fig. 6). He was discharged from hospital on oral khellin, $200 \mathrm{mg}$. daily, and maintained his improvement over the next three months. A further study of this patient is described on page 57.

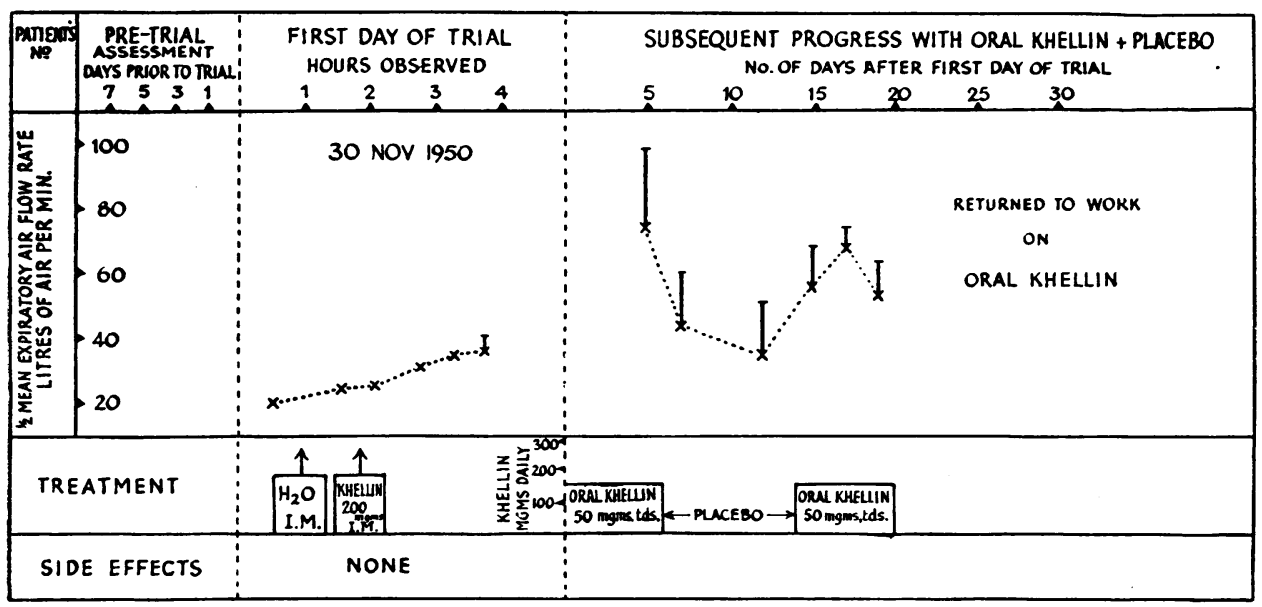

FiG. 6

Patient No. 3.-A boy, aged 14, had been subject to extremely severe attacks of asthma with continuous dyspnoea between the attacks and wheezing since the age of 2 .

Unfortunately, this lad had no pre-trial assessment, but he was observed on eight different days over a 42-day period while receiving the placebo tablets; a study of his E.F.R. on these days gave us a good idea of the day-to-day variability of the degree of bronchoconstriction present (Fig. 7).

On the first day of the trial the patient was cyanosed and exhibited expiratory rhonchi over both lungs. Before and after the injection of water his E.F.R. was 35 and 32 litres per minute respectively. After an intramuscular injection of khellin, his clinical condition and E.F.R. gradually improved, until two and a half hours after the injection the cyanosis and rhonchi had disappeared and the E.F.R. was 55 litres per minute.

He was then given oral khellin, $50 \mathrm{mg}$. twice daily. Five days after his injection and after receiving oral khellin for three days, his E.F.R. had risen to 63 litres per minute. This is the highest reading obtained over more than 130 days' observation. After taking khellin for one week, he received placebo tablets for one week, when he became so much worse that he required frequent injections of adrenaline. One record of his E.F.R. obtained at this time was only 25 litres per minute, and this was made one hour after an injection of 5 minims $(0.3 \mathrm{ml}$.) of adrenaline, $1: 1000$. Oral khellin was then given again and his asthma attacks ceased. He was discharged from hospital and continued to take khellin by mouth for 43 days, during which time he remained free from attacks, and his parents stated that he was better than they had known him since infancy. During a further 42 days on placebo tablets his asthma attacks returned, though the severity was stated to be less, and they again disappeared when khellin was restarted. Despite the apparent clinical improvement on khellin, there is no striking difference between his measured E.F.R. values during these recent treatment and control periods. 


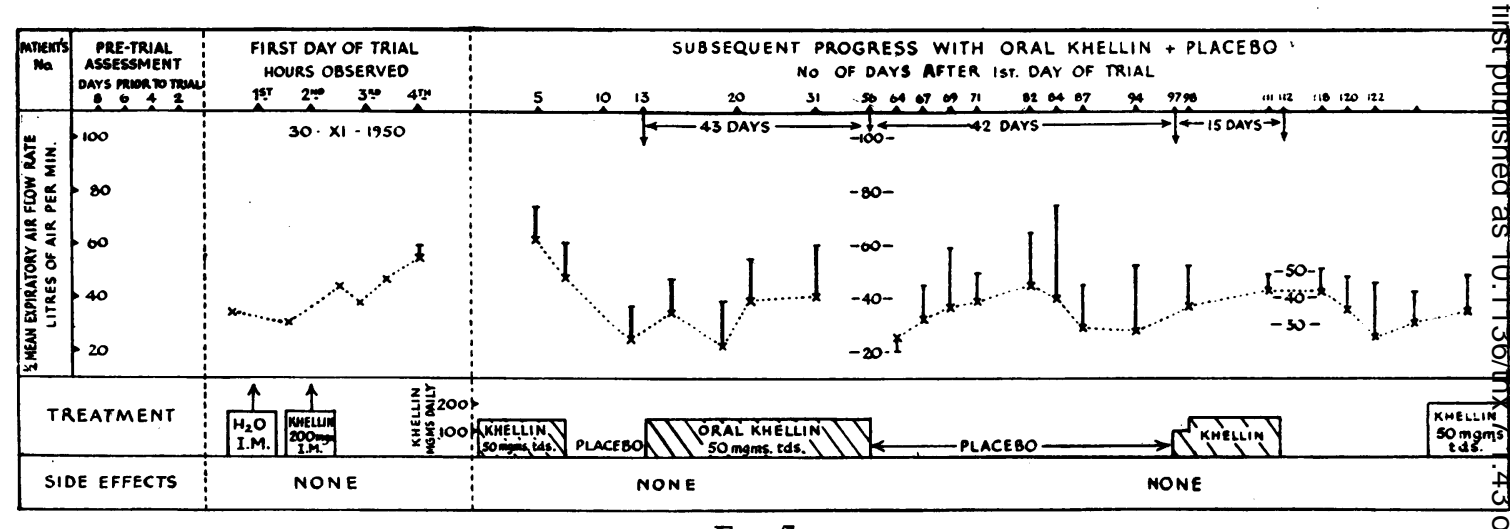

FIG. 7

Patient No. 4.-A man, aged 39, had been under treatment for asthma for many years. Severe attacks were rare, but he was constantly wheezing and dyspnoeic on exertion. In his pre-trial assessment his E.F.R. values were found to be 16 and 24 litres per minute before adrenaline and 40 to 56 litres per minute after the inhalation of adrenaline. On the first day of the trial the E.F.R. was found to be 16 litres per minute before and after subcutaneous injection of water. Clinically, he was cyanotic and had steady expiratory and inspiratory rhonchi. No change in clinical condition or in E.F.R. values were noted over a period of three hours after an intramuscular injection of $300 \mathrm{mg}$. of khellin. Twenty-four hours later the cyanosis had disappeared and the expiratory rhonchi were greatly reduced; the E.F.R. was 61 litres per minute before adrenaline and 89 litres per minute after the inhalation of adrenaline.

Subsequently he was given khellin, $50 \mathrm{mg}$. thrice daily by mouth, and improved, with E.F.R. values between 40 and 45 litres per minute.

He deteriorated when placebo tablets were substituted, and improved again when khellin was given for a second time. Side effects proved troublesome, and at first he could tarely tolerate more than $150 \mathrm{mg}$. of khellin daily by mouth. Later he received enteric-protected tablets and it became possible to increase his dose to $300 \mathrm{mg}$. daily. On this dosage the peak E.F.R. increased to 67 litres per minute before adrenaline, rising to 108 litres per minute after an adrenaline inhalation. The variations in the E.F.R. during treatment and control periods before and after adrenaline can be seen in Fig. 8 and Table I. Further studies of this patient are described on page 58.

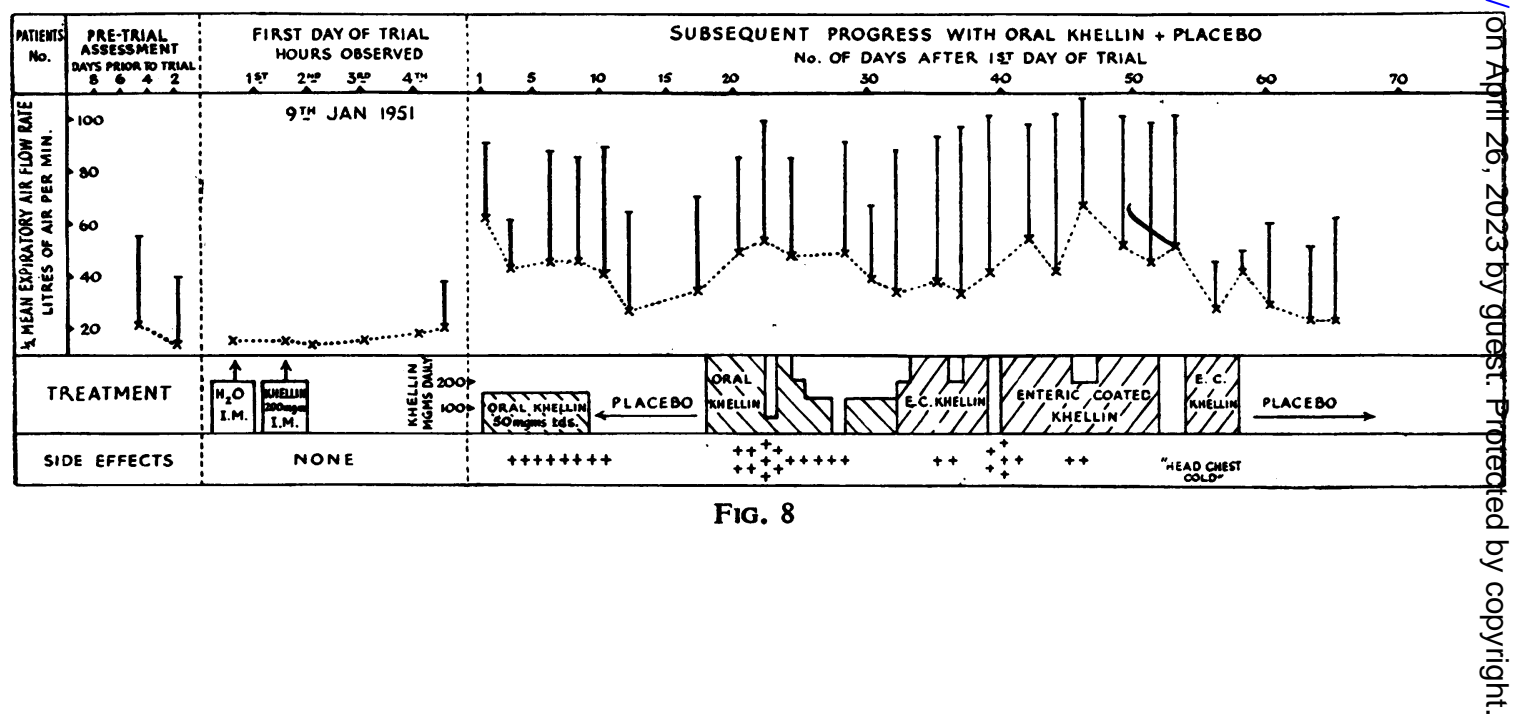


Patient No. 5.-This was a man, aged 38, with a clinical diagnosis of chronic bronchitis and emphysema. During his pre-trial assessment the E.F.R. ranged from 50 to 52 litres per minute and increased to 68 to 63 litres per minute after the inhalation of adrenaline.

The E.F.R. gradually increased after the intramuscular injection of $300 \mathrm{mg}$. khellin to 61 litres per minute in three hours. At the end of this period, the rhonchi were slightly diminished, but there was no other clinical change. During his first period of oral khellin, $50 \mathrm{mg}$. thrice daily, the E.F.R. was maintained at the improved level of between 61 and 64 litres per minute. Clinically, this improvement was overshadowed by severe side effects. He noticed, however, that he could walk up the three flights of stairs to his flat without stopping, which normally he was unable to do, and his wife stated that his customary nocturnal wheezing had ceased. No rhonchi were audible. During the placebo period, the E.F.R. fell to his base-line level, and nocturnal wheezing returned. During his second period of khellin therapy the E.F.R. again improved, but side effects were so severe that treatment could not be continued (Fig. 9).

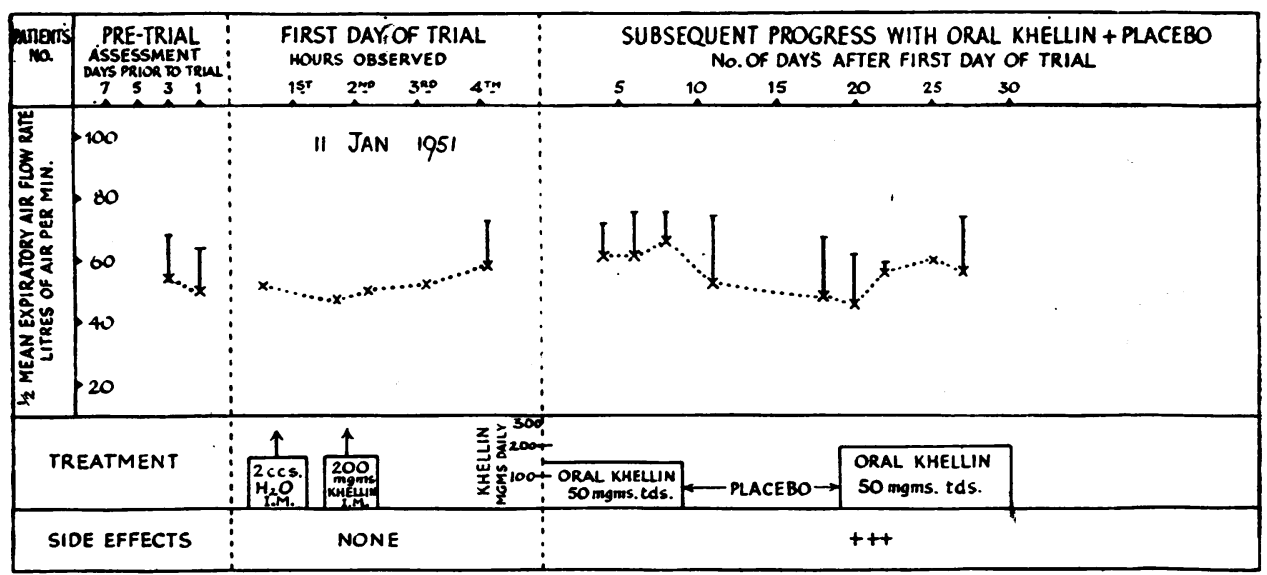

Fig. 9

In Table I a mean base-line level has been estimated for each patient before $(\alpha)$ and after $(\beta)$ the inhalation of adrenaline. The percentage change from these base-line values has been estimated, one hour, four hours, and 24 hours after a single intramuscular injection of khellin and also during the periods of administration of oral khellin and of placebo tablets.

All patients but one showed a greater increase in E.F.R. during their first period on oral khellin than during the second. The one exception is No. 4, who received a larger dose of khellin during the second period. This suggests that the intramuscular injection of khellin enhanced the effect of the first period of oral khellin.

The vital capacity data have been treated in the same way as the E.F.R. data and are presented in Table II.

In Table III the variations in the E.F.R. and V.C. values in relation to treatment have been compared. The values have been expressed as a percentage change over the base-line level. It will be noted that the E.F.R. and V.C. show a similar trend when expressed in this way. 


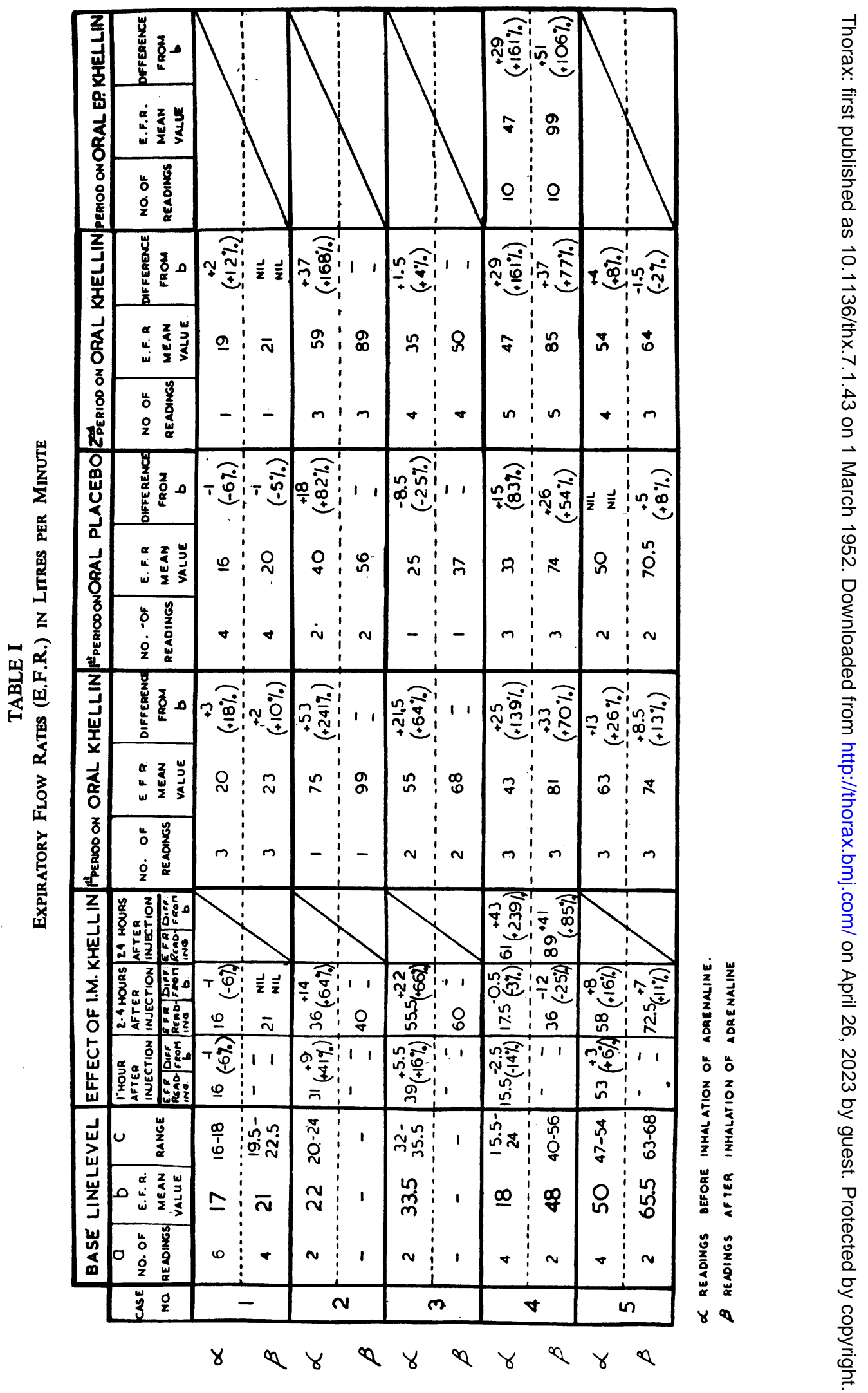




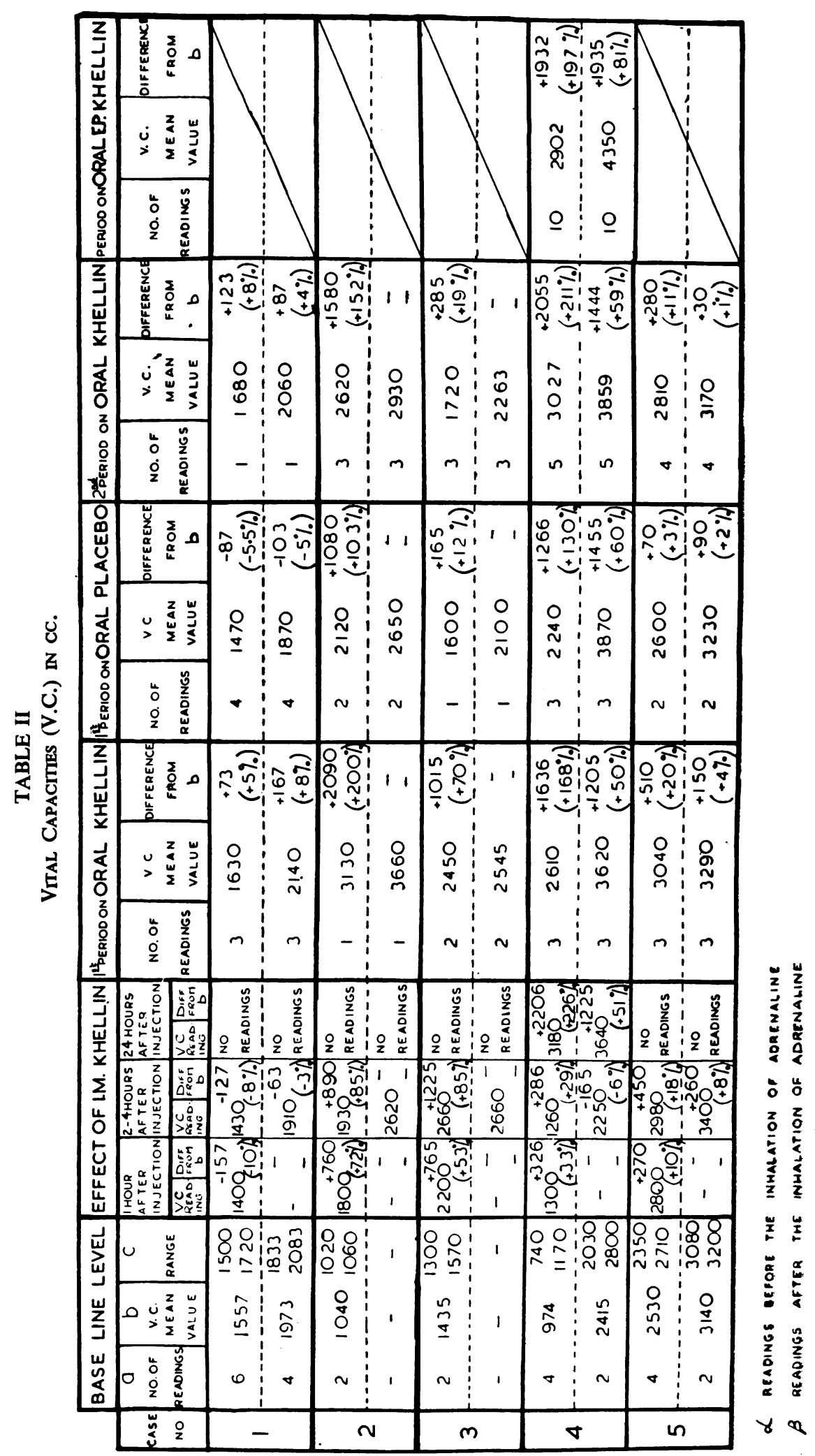

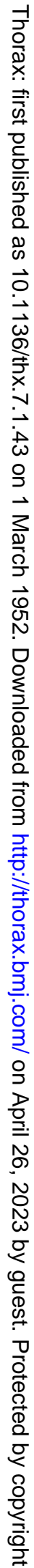


TABLE III

Comparison of the Changes in the Vital Capacities and Expiratory flow Rates of Patients 1-5 Treated with Khellin*

\begin{tabular}{|c|c|c|c|c|c|c|c|}
\hline \multirow[b]{2}{*}{$\begin{array}{c}\text { Patient } \\
\text { No. }\end{array}$} & \multirow[b]{2}{*}{$\begin{array}{l}\text { Method } \\
\text { of } \\
\text { Assess- } \\
\text { ment }\end{array}$} & \multicolumn{6}{|c|}{ Percentage Change over Base-Line Level } \\
\hline & & $\begin{array}{l}1 \mathrm{Hr} . \\
\text { after } \\
\text { Intra- } \\
\text { muscular } \\
\text { Khellin }\end{array}$ & $\begin{array}{l}2 \text { Hrs. } \\
\text { after } \\
\text { Intra- } \\
\text { muscular } \\
\text { Khellin }\end{array}$ & $\begin{array}{l}24 \text { Hrs. } \\
\text { aftet } \\
\text { Intra- } \\
\text { muscular } \\
\text { Khellin }\end{array}$ & $\begin{array}{l}\text { 1st Period } \\
\text { on Oral } \\
\text { Khellin }\end{array}$ & $\begin{array}{c}\text { 1st Period } \\
\text { on } \\
\text { Placebo }\end{array}$ & $\begin{array}{l}\text { 2nd Period } \\
\text { on Oral } \\
\text { Khellin }\end{array}$ \\
\hline 1 & $\begin{array}{l}\text { E.F.R. } \\
\text { V.C. }\end{array}$ & $\begin{array}{r}-6 \\
-10\end{array}$ & $\begin{array}{l}-6 \\
-8\end{array}$ & & $\begin{array}{r}+18 \\
+5\end{array}$ & $\begin{array}{l}-6 \\
-5 \cdot 5\end{array}$ & $\begin{array}{r}+12 \\
+8\end{array}$ \\
\hline 2 & $\begin{array}{l}\text { E.F.R. } \\
\text { V.C. }\end{array}$ & $\begin{array}{l}+41 \\
+72\end{array}$ & $\begin{array}{l}+64 \\
+85\end{array}$ & & $\begin{array}{l}+241 \\
+200\end{array}$ & $\begin{array}{r}+82 \\
+103\end{array}$ & $\begin{array}{l}+168 \\
+152\end{array}$ \\
\hline 3 & $\begin{array}{l}\text { E.F.R. } \\
\text { V.C. }\end{array}$ & $\begin{array}{l}+16 \\
+53\end{array}$ & $\begin{array}{l}+66 \\
+85\end{array}$ & & $\begin{array}{l}+64 \\
+70\end{array}$ & $\begin{array}{l}-25 \\
+12\end{array}$ & $\begin{array}{r}+4 \\
+19\end{array}$ \\
\hline 4 & $\begin{array}{l}\text { E.F.R. } \\
\text { V.C. }\end{array}$ & $\begin{array}{l}-14 \\
+33\end{array}$ & $\begin{array}{r}-3 \\
+29\end{array}$ & $\begin{array}{l}+239 \\
+215\end{array}$ & $\begin{array}{l}+139 \\
+168\end{array}$ & $\begin{array}{r}+83 \\
+130\end{array}$ & $\begin{array}{l}+161 \\
+211\end{array}$ \\
\hline 5 & $\begin{array}{l}\text { E.F.R. } \\
\text { V.C. }\end{array}$ & $\begin{array}{r}+6 \\
+10\end{array}$ & $\begin{array}{l}+16 \\
+18\end{array}$ & & $\begin{array}{l}+26 \\
+20\end{array}$ & $\begin{array}{l}\text { Nil } \\
+3\end{array}$ & $\begin{array}{r}+8 \\
+11\end{array}$ \\
\hline Totals & $\begin{array}{l}\text { E.F.R. } \\
\text { V.C. }\end{array}$ & $\begin{array}{r}+43 \\
+158\end{array}$ & $\begin{array}{l}+137 \\
+209\end{array}$ & $\begin{array}{l}+239 \\
+215\end{array}$ & $\begin{array}{l}+488 \\
+463\end{array}$ & $\begin{array}{l}+134 \\
+242\end{array}$ & $\begin{array}{l}+353 \\
+400\end{array}$ \\
\hline $\begin{array}{l}\text { Mean of } 5 \\
\text { Patients }\end{array}$ & $\begin{array}{l}\text { E.F.R. } \\
\text { V.C. }\end{array}$ & $\begin{array}{l}+8.6 \% \\
+32 \%\end{array}$ & $\begin{array}{l}+27 \% \\
+42 \%\end{array}$ & & $\begin{array}{l}+98 \% \\
+92.6 \%\end{array}$ & $\begin{array}{l}+27 \% \\
+48 \%\end{array}$ & $\begin{array}{l}+70.6 \% \\
+80 \%\end{array}$ \\
\hline
\end{tabular}

* No adrenaline data included in this table.

\section{Patients not Improved By Khellin}

The remaining seven cases showed no conclusive evidence of a response to khellin. They included two chronic asthmatics, two pneumoconiotics with a positive response to the adrenaline test, and three cases of chronic bronchitis with severe emphysema.

The two chronic asthmatics appeared to respond clinically to the drug, but unfortunately our objective data are incomplete. Of the remaining five patients, none showed a response to a single intramuscular injection of khellin. In three, side effects were so severe that an adequate trial with oral khellin proved impossible. One of the other two patients was too ill for us to assess the effects of the drug, and the remaining patient showed no response, despite an adequate trial.

\section{FURTHER STUDIES}

Further studies have been carried out to determine when the peak effect of a single intramuscular injection of khellin is reached and how long the effect lasts. The response to a single large dose of khellin given by mouth, and the varying response with varying doses, has also been investigated. These later studies have been related to khellin blood-level findings. The data on three patients (two have already been described) are presented to illustrate these points. 
Patient No. 2.-This man maintained his improvement for three months on oral khellin, when placebo tablets were substituted, and he quickly became so much worse that he was re-admitted to hospital. He was again orthopnoeic, cyanosed, and wheezy, with expiratory and inspiratory rhonchi. On April 13, the E.F.R. was 25 litres per minute before adrenaline and 34 litres per minute after. After three days' rest in hospital he improved, and the E.F.R. rose to 60 litres per minute before adrenaline and 70 litres per minute after. Next morning, on April 17, he was given a single intramuscular injection of $400 \mathrm{mg}$. khellin, and the V.C. and E.F.R. before and after adrenaline were recorded twice daily for three days. The results are shown in Fig. 10. The E.F.R. reached a peak of 92 litres before adrenaline and 103 litres per minute after adrenaline six and a half hours after the injection, and then gradually waned over the next 40 hours.

Later, on April 26, 28, and 30 he was given intramuscular injections of $400 \mathrm{mg}$. of khellin on alternate days. There was no evidence of an enhanced response following the second and third intramuscular injections. During the following week, he was given no treatment; the E.F.R. gradually waned to 20-22 litres per minute. Two injections of sterile water elicited no response.

Finally, during a four-week period he received different doses of khellin by mouth. At the end of the first period on $200 \mathrm{mg}$. daily by mouth, the E.F.R. had risen from 20 to 49 litres per minute. At the end of the second period after receiving $300 \mathrm{mg}$. daily by mouth, it had risen to 111 litres per minute. This peak was recorded 24 hours after ceasing to take khellin. During the following week the E.F.R. quickly fell to 30 litres per minute while placebo tablets were being given. In the fourth week he took $300 \mathrm{mg}$. khellin daily, and at the end of this time the E.F.R. had risen to 66 litres per minute. This peak, which was reached after $1.3 \mathrm{~g}$. of khellin had been

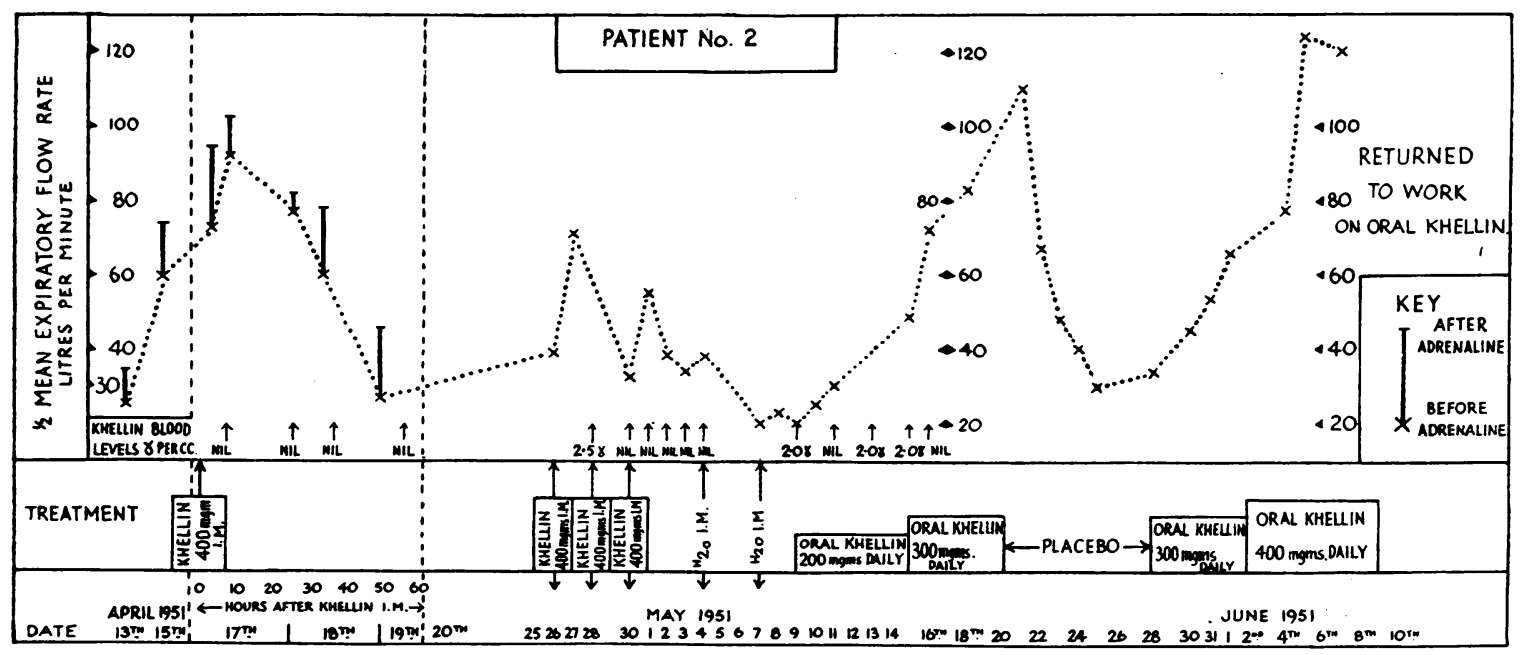

Fig. 10 


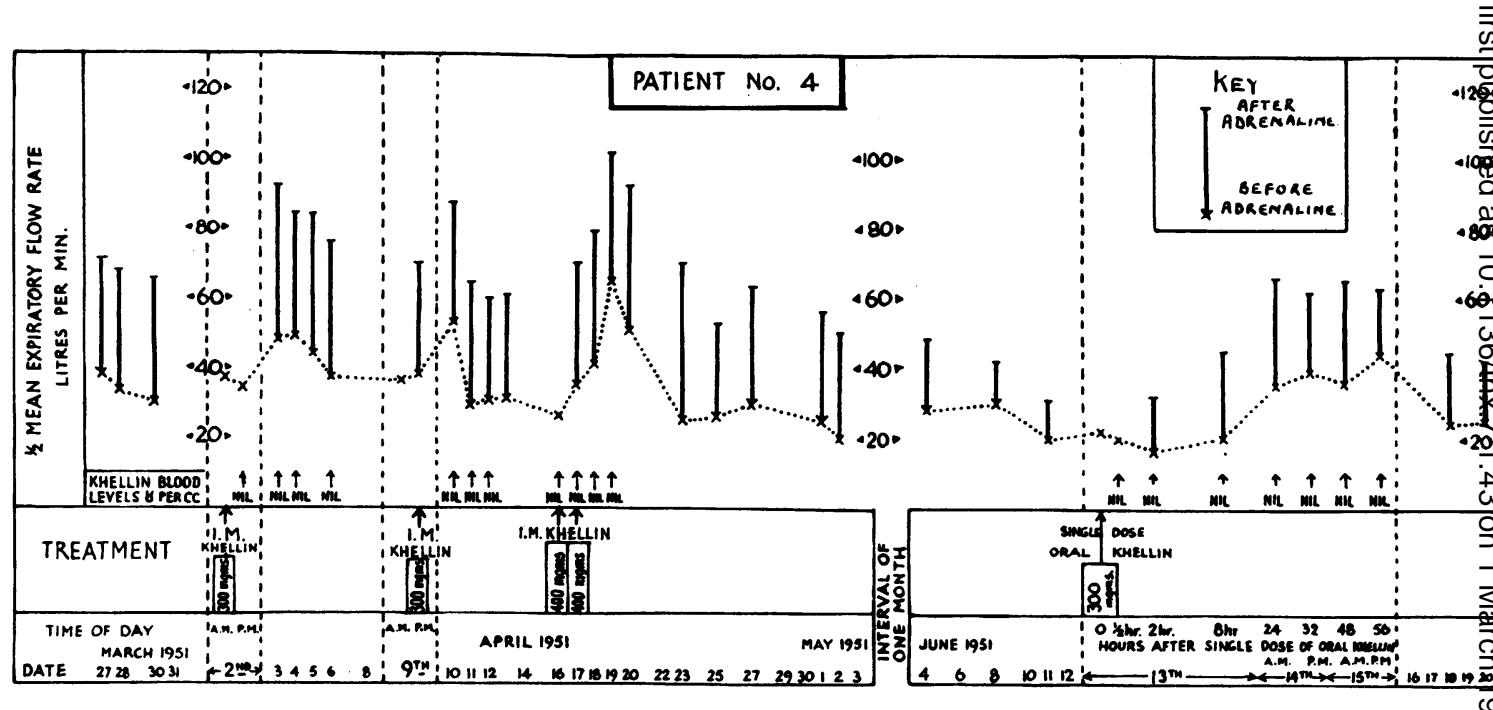

FIG. 11

given over a five-day period, is considerably less than the previous peak obtained after $3 \mathrm{~g}$. of khellin over 12 days; and provides evidence for a cumulative effect of the drug.

This patient suffered no side effects from oral khellin, and took a dose of $400 \mathrm{mg}$. daily during the final period when the E.F.R. rose to a peak of 124 litres per minute. When this point was reached, no further improvement occurred after an adrenaline inhalation.

Patient No. 4.-Further studies are summarized in Fig. 11. After each of two single intramuscular injections of $300 \mathrm{mg}$. on April 2 and 9, the peak response occurred 24 hours after the injection. After the injection on April 2, the response was maintained for roughly 72 hours; after the injection on April 9, improvement lasted less than 48 hours.

On April 16, when the E.F.R. was 26 litres per minute, he was given a single intramuscular injection of $400 \mathrm{mg}$. khellin. Twenty-four hours later the E.F.R. had risen to 35 litres per minute, and another injection of $400 \mathrm{mg}$. was given. On April 18 the E.F.R. had risen to 41 litres per minute, and three days later to a peak of 65 litres per minute, rising to 102 litres per minute after adrenaline. On the next day the E.F.R. had begun to fall and then gradually waned. These findings strongly suggest that intramuscular injections given consecutively within a 24 -hour period produce a cumulative effect.

On June 13 he received a single oral dose of $300 \mathrm{mg}$. khellin. There was no symptomatic or objective change for one hour. After one and a half to two hours, he developed an acute asthmatic attack and the E.F.R. had fallen to 16 litres per minute. The severity of this attack necessitated an inhalation of adrenaline which raised the E.F.R. to 32 litres per minute. It seems possible that this asthmatic attack was the result of reflex bronchospasm from gastro-intestinal irritation by the single large oral dose of khellin. His condition gradually improved; in eight hours from the oral dose the E.F.R. was 
20 litres per minute, in 24 hours it had risen to a peak of 35 litres per minute, and in 56 hours it was 34 litres per minute. There were no other side effects, such as nausea or vomiting, after the single large oral dose.

Patient No. 36.-This patient, a chronic asthmatic, aged 50 , is included, since he shows a similar picture to the previous patient after a single intramuscular injection of khellin. He achieved a peak response $25 \frac{1}{2}$ hours after an injection of $400 \mathrm{mg}$. khellin (Fig. 12). Thirty and a half hours after the injection the E.F.R. was good but lower, but by 73 hours it had returned to its original level.

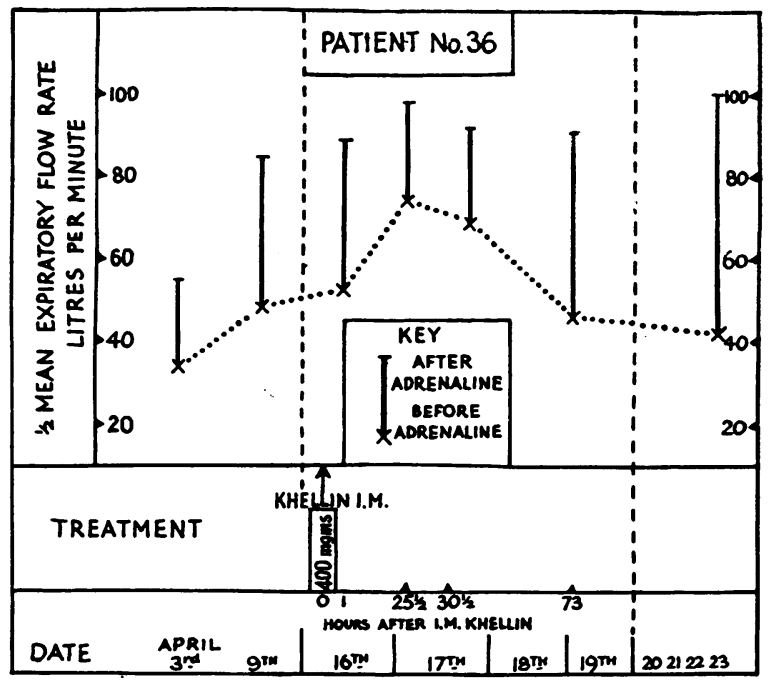

FIG. 12

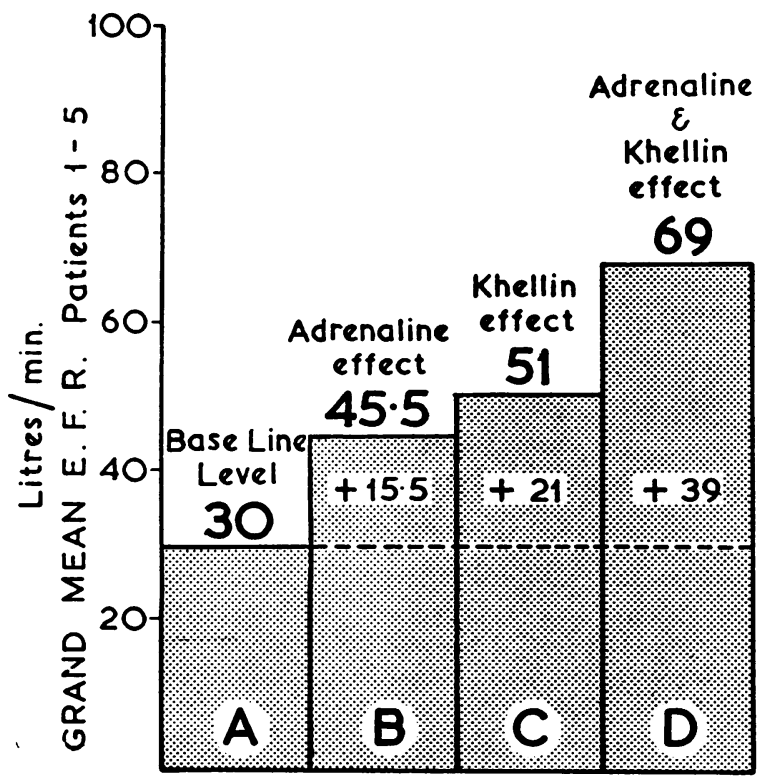

Fig. 13.-Values for Columns $C$ and $D$ have been compiled from the mean E.F.R. values listed under first period on oral khellin in Table II. Values for Columns $A$ and $B$ have been compiled from the mean E.F.R. values listed under base-line level in the case of Patients 1,4 , and 5. In the case of Patients 2 and 3 the mean E.F.R. values listed under first period on oral placebo have been used.

\section{The Combined ACtion of Adrenaline and Khellin}

The mean E.F.R. values of patients 1 to 5 are shown in Table $I$ in relation to treatment with khellin and adrenaline. The figures listed in this table have been used to compile Fig. 13, which gives the mean E.F.R. value for all five patients $(a)$ while receiving no treatment, (b) after a 15minute inhalation of adrenaline, (c) while receiving khellin by mouth, and (d) after an adrenaline inhalation while receiving khellin. When the results are expressed in this manner it can be seen that the adrenaline effect is almost equal to the khellin effect, and when adrenaline and khellin therapy are combined the ultimate effect of the two drugs appears to be additive. 
The E.F.R. results of patients 1,4 , and 5 are sufficiently numerous to warrant statistical treatment. The estimated mean E.F.R.s in this statistical analysis were :

\begin{tabular}{|c|c|c|c|c|}
\hline \multirow{2}{*}{ Subject } & \multirow{2}{*}{ Base Line } & \multirow{2}{*}{ Adrenaline } & \multicolumn{2}{|c|}{$\begin{array}{l}\text { 1st and 2nd } \\
\text { Periods Combined }\end{array}$} \\
\hline & & & Khellin & Both \\
\hline $\begin{array}{l}1 \\
4 \\
5\end{array}$ & $\begin{array}{l}16 \cdot 7 \\
18 \cdot 1 \\
50 \cdot 4\end{array}$ & $\begin{array}{l}21 \cdot 0 \\
47 \cdot 9 \\
65 \cdot 7\end{array}$ & $\begin{array}{l}19 \cdot 5 \\
45 \cdot 4 \\
57 \cdot 8\end{array}$ & $\begin{array}{l}22 \cdot 7 \\
84 \cdot 3 \\
69 \cdot 2\end{array}$ \\
\hline
\end{tabular}

It can be seen that the response to the drugs varied from subject to subject to a significant extent. This is suggested by the large interaction mean square in the following analysis of variance :

\begin{tabular}{lr|c}
\hline Degrees of Freedom & Mean Square \\
\hline Additive effects & 5 & 33.0697 \\
Interactions & 6 & $4 \cdot 4530 \mathrm{xx}$ \\
Error & 47 & $0 \cdot 1507$ \\
\hline
\end{tabular}

The mean square is almost 30 times the error variance. When the results for each subject were analysed separately, in no case was it found that the effects of khellin and adrenaline were interacting:

\begin{tabular}{|c|c|c|c|c|c|c|c|}
\hline & & \multirow{3}{*}{ D.F. } & \multicolumn{5}{|c|}{ Subject } \\
\hline & & & \multirow{2}{*}{$\frac{1}{\text { Mean Sq. }}$} & \multirow{2}{*}{ D.F. } & 4 & \multirow{2}{*}{ D.F. } & 5 \\
\hline & & & & & Mean Sq. & & Mean Sq. \\
\hline $\begin{array}{l}\text { Effect of khellin } \\
\text { I̋ , adrenaline } \\
\text { Interaction .. } \\
\text { Error } \quad . .\end{array}$ & $\begin{array}{l}\cdots \\
\cdots \\
\cdots \\
\cdots\end{array}$ & $\begin{array}{r}1 \\
1 \\
1 \\
14\end{array}$ & $\begin{array}{l}0.3127 \times x \\
0.8291 \times x \\
0.0229 \\
0.0166\end{array}$ & $\begin{array}{r}1 \\
1 \\
1 \\
18\end{array}$ & $\begin{array}{l}24 \cdot 8067 \mathrm{xx} \\
36 \cdot 6233 \mathrm{xx} \\
0 \cdot 0532 \\
0 \cdot 2503\end{array}$ & $\begin{array}{r}1 \\
1 \\
1 \\
15\end{array}$ & $\begin{array}{l}0.6389 \\
2.9109 \times x \\
0.0821 \\
0.1563\end{array}$ \\
\hline
\end{tabular}

On all subjects the effect appears simply additive, adrenaline having the same effect on the patient whether or not he had had khellin, and vice versa. The data give no evidence of a reduced or enhanced effect from combining the drugs.

It should be noted, however, that Patient 2 at the end of six days' treatment with $400 \mathrm{mg}$. khellin daily by mouth attained a peak of 124 litres per minute, which is almost a normal reading for a man of his age and build, and that after this an inhalation of adrenaline produced no further improvement. 


\section{SIDE EFFECTS}

At present side effects, particularly nausea, are frequent and troublesome after the therapeutic use of khellin. Armbrust and Levine (1950) reported "uncomfortable " side effects, anorexia, nausea, and dizziness, in $60 \%$ of 53 cases of angina pectoris treated with oral khellin. Rosenman and others (1950) give a similar incidence for 30 cases, $53 \%$ experiencing significant side effects. In 40 cases treated with oral khellin, we found that by far the most important side effects are nausea and anorexia with occasional vomiting. A few patients have complained of somnolence, dizziness, and irritability while taking the drug, but these have been relatively trivial in comparison with nausea and would in no case have interfered with continued administration. We have not encountered any skin eruptions during treatment with the drug.

The incidence and severity of nausea in our patients is shown in Table IV. Some degree of nausea occurred in $26(65 \%)$ of the cases. In four cases $(10 \%)$ this was relatively mild and did not interfere with treatment. In nine $(22.5 \%)$ it was sufficiently severe to necessitate suboptimal dosage and in $13(32.5 \%)$ it was prohibitive and led to the abandonment of oral therapy.

TABLE IV

INCIDENCE OF NAUSEA IN THE Series

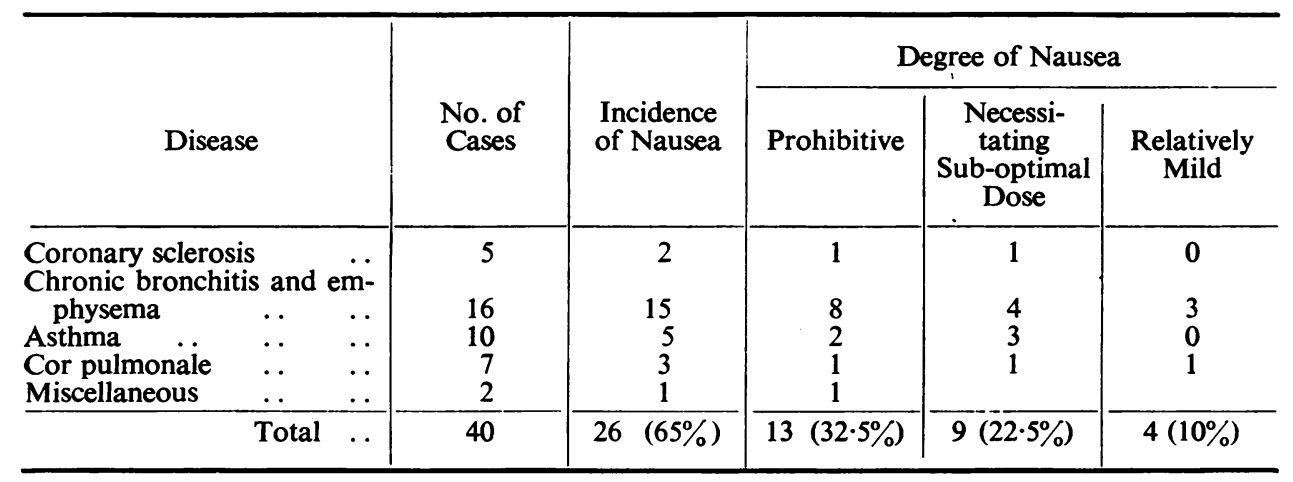

When severe the nausea is more or less continuous and is particularly incapacitating. It may be associated with almost complete anorexia and vomiting occurs once or twice in the day. The patient rapidly becomes dejected, miserable, and apathetic, often despite dramatic amelioration of his dyspnoea. In less severe cases the nausea is intermittent and is often controllable by simple reduction of dosage. In a few cases, the nausea appears almost from the very first dose of the drug. More usually, however, it is delayed until the third or fourth day of treatment or even later. If nausea is severe, it tends to persist for 24 to 48 hours after the drug is discontinued. Side effects are always more obtrusive in ambulant patients than in those resting quietly in bed. This possibly explains the apparently low incidence in cases of chronic cor pulmonale.

The delay in the appearance of symptoms and their tendency to persist after the drug is stopped suggest that the effect is cumulative and might be central in 
origin. On the other hand, side effects after intramuscular injections are much less marked. Four patients, who were unable to tolerate the drug orally, were given $300 \mathrm{mg}$. daily intramuscularly for 10 days. All began to experience nausea on about the fourth day of treatment and two vomited. In one case, injections had to be discontinued, but in the other three the nausea quickly wore off and by the end of a week the only untoward symptom was mild anorexia in two of the cases.

These findings suggest that the nausea is largely due to a local irritant effect on the gastric mucosa, but a central effect cannot be entirely excluded. It was hoped that the local effect might be overcome by using a tablet in which the individual khellin granules were coated with stearic acid so that disintegration of the tablet with liberation of the drug would be delayed until the small intestine was reached. Use of these "enteric-protected" tablets has certainly reduced the incidence and severity of nausea and has enabled some patients to tolerate an effective dose of the drug which was previously impossible. However, a further reduction in the incidence of side effects will be essential before administration of the drug orally will be possible in every case.

No significant changes have been noted in the blood pressure, haemoglobin levels, or red or white cell counts after intramuscular or oral khellin administration.

\section{BLOOD LEVELS OF KHELLIN}

The blood level of khellin has been estimated in a number of cases after both intramuscular and oral medication. The method of estimation employed is accurate to $\pm 0.5 \mu \mathrm{g}$. per ml. of blood. We hoped that it might be possible to relate the level of the drug in the blood to its physiological effect and thus obtain a simple guide to the best dosage. Our preliminary findings indicate that this is unlikely to prove feasible. The drug is rapidly absorbed by the intramuscular route, reaching a peak blood level in half to one hour, but then rapidly falling to undetectable levels. For example, in patient No. 2, after $400 \mathrm{mg}$. intramuscularly, the blood levels half, one, two, and four hours after injection were $2.5 \mu \mathrm{g}, 2.5 \mu \mathrm{g}$, less than $0.9 \mu \mathrm{g}$. per ml., and zero respectively. A similar type of curve, though more. delayed and variable, follows oral administration. Values are by no means constant from patient to patient. In patients receiving continuous medication, early morning levels have been estimated on a number of occasions before any drug has been given that day. No khellin has been detected in any of these samples.

\section{DISCUSSION}

Measurement of the expiratory flow rate in the manner described has proved a convenient method for assessing changes in the ventilatory capacity and thus variations in the bronchial lumen. Variations in the expiratory flow rate and vital capacity in individuals showed a similar trend when expressed as a percentage change (Table III) and this point merits further investigation. However, it has been shown (Gilson and Hugh-Jones, 1949) that the vital capacity is a poor index of ventilatory function and that the maximum breathing capacity bears a much closer relationship to the clinical grade of dyspnoea. The measurement of the expiratory 
flow rate combines the advantages of the maximum breathing capacity test with the simplicity of the vital capacity method.

In the early stages of this work a number of difficulties seriously interfered with our original plan of investigation. In the first place, as already indicated, the high incidence of side effects prevented an adequate trial of oral khellin in several cases. A second difficulty was the incidence of intercurrent respiratory infections, particularly among the cases with chronic bronchitis, which tended to obscure the picture. Three of the 12 patients died during the influenzal epidemic in the early months of 1951. Because of these difficulties, our data are not complete, and we cannot discuss the 12 cases as a whole. Five patients, however, showed improved expiratory flow rates after khellin and our objective data on these patients are sufficiently complete to justify some provisional conclusions.

The bronchodilator effect of a single intramuscular injection of khellin is delaved for at least an hour, is gradual in onset, and the peak effect is not attained until after six to 24 hours. On the other hand, once an effect appears it may be sustained over 24 hours or even longer. This observation is at variance with the findings of Kenawy and others (1950) and of Rosenman and others (1950) who state that a response may be seen within five to 10 minutes, with a peak in half to one hour. We have not observed a similar rapid response in any of our cases. It seems unlikely that this delayed physiological effect can be explained by a delay in absorption from the injection site, for we have found that the blood level after intramuscular injection reaches a peak in half to one hour, and by the time the bronchodilator effect is significant no khellin can be detected in blood samples.

In addition to the sustained effect of single doses of khellin, repeated daily dosage by the intramuscular or oral route appears to have a cumulative bronchodilator action. This cumulative effect is well exemplified from the further study of cases 2 and 4 (Figs. 10 and 11).

As a corollary to its sustained bronchodilator action, khellin appears to be especially effective in reducing the frequency and severity of acute attacks in the chronic asthmatic. This effect was noted in patient number 3 and has been observed in a number of other cases not included in the present series.

We have insufficient data to determine the best dosage, by intramuscular or oral routes : $200-400 \mathrm{mg}$. as a single intramuscular injection appears to be well tolerated and to be effective in cases which respond. The oral dosage is largely determined by the patient's tolerance. However, from the data presented and from other material available, it appears that not less than $150 \mathrm{mg}$. daily is the minimum effective dose for the average adult, and $300-400 \mathrm{mg}$. daily is desirable. We have evidence that with continued administration, some degree of resistance to the drug develops, necessitating higher dosage to obtain the same effect.

The quantitative response to khellin varied in the different clinical typas. Patients with chronic asthma showed a much greater improvement in E.F.R. after khellin (from $64 \%$ to $239 \%$ ) than those with chronic bronchitis and emphysema (from $18 \%$ to $26 \%$ ). All 12 patients in the series showed improvement in E.F.R. after inhalation of adrenaline. This adrenaline effect varied between $20 \%$ and $150 \%$ and, like the khellin effect, was greater in patients with chronic asthma than in those with chronic bronchitis and emphysema. Originally it had been hoped that the adrenaline test would serve the dual purpose $\mathrm{cf}$ indicating the degree of reversible broncho- 
constriction and of providing a measure against which the effect of khellin could be judged. Our findings suggest that a modification in the interpretation of this test is necessary. When adrenaline and khellin are given together, the effect of the two drugs appears to be additive, and the response to adrenaline remains substantially the same, even at the peak of a khellin effect. This observation strongly suggests that the action of the two drugs is different. From animal experiments with khellin (Samaan, 1932 ; Anrep, Barsoum, and Kenawy, 1949) it seems very probable that its pharmacological action is on the smooth muscle in the bronchial wall. On the other hand, adrenaline inhalations, in view of their mode of administration, may act mainly on the mucous membrane lining the bronchi, although the recent work of Sheldon and Otis (1951) suggests that the subcutaneous injection of adrenaline may produce pulmonary vascular constriction rather than bronchiolar dilation in certain cases. The hypothesis of a primary mucosal effect of inhaled adrenaline leads to some interesting speculations about the pathogenesis of reversible bronchoconstriction in the different clinical types of case. In the chronic bronchitic, the adrenaline response and the khellin response are roughly equal, suggesting that the mucosa and the smooth muscle are equally affected, whereas in the chronic asthmatic the khellin response is appreciably greater than the adrenaline response, indicating that in these cases spasm of the bronchial muscle is the main cause of the reversible bronchoconstriction. These findings emphasize that reversible bronchoconstriction may be due to multiple factors, and that its most efficient relief requires a combination of drugs, each at optimal dosage. This preliminary report has been mainly concerned with the objective demonstration of the bronchodilator effect of khellin in a number of selected cases. Its use as a practical therapeutic agent still remains to be determined. However, its property of producing a sustained increase in the ventilatory capacity may be of the greatest value in the management of certain chronic asthmatics and chronic bronchitics in whom a true bronchospasm is a significant contributory factor. The main problem still requiring solution is the high incidence of side effects when the drug is given orally, for at present in many cases the only feasible method of maintaining adequate dosage is by daily intramuscular injection which presents obvious difficulties in practice.

We consider that the results are sufficiently encouraging to warrant further work on the action and clinical use of khellin as a bronchodilator.

\section{SUMMARY}

Some of the difficulties in the investigation of a bronchodilator drug are discussed.

Variations in the bronchial lumen are accompanied by corresponding variations in ventilatory capacity. The ventilatory capacity has been assessed by measuring half the mean expiratory flow rate (E.F.R.) over the first three-quarter second period of six consecutive expiratory vital capacity tracings using a simple spirometer and a fast-moving synchronous kymograph. This measure (E.F.R.) correlates well with the observed maximum breathing capacity $(r=+0.927)$ and is a simple and convenient method in clinical work. 
This method, together with the vital capacity measurement, has been used to assess the bronchodilator effect of khellin by the intramuscular and oral route and a preliminary report is presented on a series of 12 cases.

In a selected group of 12 cases with a positive adrenaline response, the E.F.R. was improved in three cases of chronic asthma by $64 \%$ to $239 \%$, and in two cases of chronic bronchitis with emphysema by $18 \%$ to $26 \%$. The findings in the remaining seven cases were inconclusive.

The action of khellin is slow to appear, but the effect of single doses is sustained over a 24 to 48 -hour period and the effect of repeated doses is cumulative.

The effects of khellin, of an adrenaline inhalation, and of the two combined have been compared. The combined effect appears in the main to be additive, suggesting that the mode of action of the two drugs is different.

Side effects, mainly nausea, are frequent, and occur principally after oral administration. They are diminished by the use of an "enteric-protected" tablet, and are least after intramuscular injection.

We should like in the first place to express our appreciation to Mr. T. E. Bromley, S.R.N., charge nurse to the Silicosis Treatment Centre, for his care and skill in carrying out the spirometric measurements. We would also like to express our thanks to Dr. Pamela Beal, house physician at the City General Hospital, Stoke-on-Trent, for constant help throughout this investigation, to P. D. Oldham for statistical analyses, and to Dr. C. M. Fletcher, Dr. J. C. Gilson, and Dr. A. J. McCall for criticizing the manuscript.

Our sincere acknowledgments are due to Bengers Laboratories, Ltd. for the generous supplies of khellin which enabled this investigation to be undertaken.

\section{REFERENCES}

Anrep, G. V., Barsoum, G. S., and Kenawy, M. R. (1949). J. Pharm. Pharmacol., $1,164$. and Misrahy, G. (1946). Brit. Heart J., 8, 171.

- and Misrahy, G. (1946). Lancet, 1, 557.

Armbrust, C. A., and Levine, S. A. (1950). Amer. J. Med. Sci., 220, 127.

Comroe, J. H. (1950). Methods in Medical Research, 2, pp. 209-214.

Gilson, J. C., and Hugh-Jones, P. (1949). Clin. Sci., 7, 185.

Hermannsen, J. (1933). Z. ges. exp. Med., 90, 130.

Kennedy, M. C. S. (1949). Beitr. Silikose-Forsch., 10, 21.

- (1952). In the press.

Kenawy, M. R., Barsoum, G. S., and Bagoury, M. M. (1950). Eye, Ear, Nose, Thr. Mon., $29,79$. Mustapha, I. (1879). C.R. Acad. Sci., Paris, 89, 442.

Rosenman, R. H., Fishman, A. P., Kaplan, S. R., Levin, H. G., and Katz, L. N. (1950). J. Amer. med. Ass., 143, 160.

Rossier, P. H., and Méan, H. (1936). Act. Soc. helv. Sci. nat., 117, 356.

Samaan, K. (1932). Quart. J. Pharm., 5, 6.

Sheldon, M. B., and Otis, A. B. (1951). J. appl. Physiol., 3, 513.

Späth, E., and Gruber, W. (1938). Ber. Dtach. chem. Ges., 71, B 106.

(1941a). Ibid., 74, B 1492.

(1941b). Ibid., 74, B 1549.

Whitfield, A. G. W., Arnott, W. M., and Waterhouse, J. A. H.(1950). Quart. J. Med., 19, (n.s.), 319. 